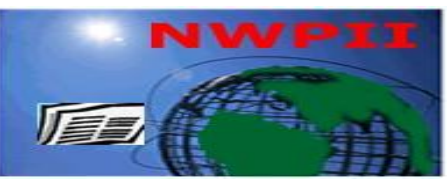

American Journal of Biomedical Sciences

ISSN: 1937-9080

nwpii.com/ajbms

\title{
Phytochemical Confinement in Sections of Pleurotus Tuber-regium (King Tuber Mushroom) Basidocarp
}

\author{
Reginald C. Ohiri*, Benjamin A. Amadi and Fegor E. Isoje
}

Department of Biochemistry, Faculty of science, University of Port Harcourt.P. M. B.5323, East-West Road, Choba, Rivers State, Nigeria.

"Corresponding Author

Reginald C. Ohiri

Department of Biochemistry, Faculty of science,

University of Port Harcourt, P. M. B. 5323, East-West Road,

Choba, Rivers State,

Nigeria.

Email: raycohiri@yahoo.com, reginald.ohiri@uniport.edu.ng

Tel:+2348038808077

Received:19 September 2018;| Revised:30 September 2018;| Accepted: 09 December 2018

\begin{abstract}
Cellular compartmentation is responsible for the restriction of most products of metabolic processes to specified regions of the organism. In this study, a quantity of $10.0 \mathrm{~kg}$ of fresh sclerotia of Pleurotus tuberregium purchased from Zarama market in Bayelsa State, Nigeria were washed, peeled and sliced. Eight kilograms of the sliced sclerotia were packed in a transparent cellophane bag and a temperature range of $33-$ $35{ }^{\circ} \mathrm{C}$ was achieved at the 3rd day. Stipes of P. tuber-regium basidiocarps were observed at the 8th day and at the 10th day, the stipes sprouted out from the perforated openings. At the 14th day, fresh basidiocarps of $P$. tuber-regium were harvested and the stipe, cap-base and pileus were immediately separated and allowed to dry at room temperature for fourteen days. The dried samples were ground and the oils were extracted by standing a mixture of $10 \mathrm{~g}$ of sample in $20 \mathrm{ml}$ of dichloromethane for 3 days. The process was repeated twice and the combined aliquot obtained were concentrated to $5 \mathrm{ml}$ and purified. Two milliliters of the extracted oil were used for gas chromatographic and mass spectroscopy analysis. The highest peaks on the chromatogram of volatile components of the oils from the pileus, cap-base and stipe were observed at 15.663 min., 15.693 min. and 15.819 min. respectively. Propanoic acid was the predominant compound observed in the pilus with a percentage value of $29.763 \%$, while Hexadecanoic acid methyl ester was predominant in both the cap-base and stipe with values of $23.638 \%$ and $26.677 \%$ respectively.
\end{abstract}

Keywords: Phytochemical, Compartmentation, Confinement, Sclerotia, Stipe, Pilus and cap-base 


\section{Introduction}

In trees and other plants, the above ground (visible) parts have remained their largest part. But in the case of macro-fungi, the visible basidiocarp is only the fruiting body of a bigger organism that is hidden either within a decomposing wood material or beneath the soil surface. One macro fungus with distinct characteristics is the Pleurotus tuberregium. $P$. tuber-regium is amongst the numerous mushrooms of the tropical rain forest of Africa. It is one mushroom that both its basidiocarp and sclerotium are of economic importance due to their nutritive and medicinal properties. Aside Africa, P. tuber-regium also grows in Asia and Australia ${ }^{[1]}$. It is a saprotroph, that produces a food storage sclerotiun upon its consumption of decaying wood. The dimitic tissue of this mushroom is composed of generative thick-walled hyphae, while its spores are cylindrical, smooth and hyaline-like in appearance [2]. The formation of infundibuliform pilus, decurrent gills and a well-developed stipe is a known characteristic of its basidiocarp ${ }^{[3]}$. The junction between the stipe and the pilus which is referred to as the cap-base (reticulum) shows an irregular netted gilled formation that transcends to the gills beneath the cap.

In mushroom and other living cells, there is always a state of metabolism, which may be either catabolic or anabolic. Though the anabolic process always surpass the catabolic process during growth, cellular compartmentation is responsible for the restriction of most products of these metabolic processes to certain regions of the organism. These compounds, which may include waste products and toxic compounds are kept out of the cytoplasmic components by their confinement in the cellular vacuoles ${ }^{[4]}$. This confinement or localization of compounds may also be affected by the site of production of such compounds. The aim of this research is to ascertain the possible confinement or localization of compounds in the different structural compartments of the basidiocarp of P. tuber-regium.

\section{Materials and Methods}

\subsection{Sample Collection, Growth, Preparation and Extraction}

A quantity of $10.0 \mathrm{~kg}$ of fresh sclerotia of $P$. tuber-regium were purchased at Zarama market in
Yenagoa Local Government area of Bayelsa State, South-South Nigeria and was taken to the University of Port Harcourt. The sclerotia were washed, peeled and the white inner part were sliced using a sterilized knife. A quantity of $8 \mathrm{~kg}$ of the sliced sclerotia was packed in a transparent cellophane bag and a thermometer was inserted. This set up was allowed to stand and a temperature range of $33-35{ }^{\circ} \mathrm{C}$ was achieved at the 3 rd day. This temperature range was maintained and at the 8th day, sprouts of $P$. tuber-regium basidiocarps were observed and the cellophane bag was randomly perforated. Stipes of the basidiocarps sprouted out from the perforated openings at the 10th day and fully grown $P$. tuberregium were harvested at the 14th day. The stipe, reticulum and pileus of the harvested mushrooms were immediately separated using a clean and sterilized knife. The different parts were allowed to dry at room temperature in a dust free environment for a period of fourteen days and the dried samples were separately ground into fine powders. The ground samples were extracted by weighing $10 \mathrm{~g}$ of the sample into a well stopper bottle and $20 \mathrm{ml}$ of dichloromethane was added. The mixtures were vigorously agitated and were left to stand for 3 days. The process was repeatedly carried out for two more times. The combined aliquot collected were concentrated on a steam berth to about $5 \mathrm{ml}$ and purified by passing through a pasture pipette packed with silica gel and anhydrous sodium sulphate on a membrane and air dried to about $2 \mathrm{ml}$ for gas chromatographic analysis.

\subsection{GC-MS Analysis of Extracts}

The mushroom extract was analysed using a combined gas chromatograph model HP 6890 and mass spectrometer model 5973 (Agilent Tech.) fitted with a capillary column HP-5 MS (5\% phenylmethylsiloxane) $30.0 \mathrm{~m}$ x $250 \mu \mathrm{m} \times 0.25 \mu \mathrm{m}$, using Helium as a carrier gas at initial column temperature $120^{\circ} \mathrm{C}$ for 5 minutes. Thereafter, the column temperature was increased at $5^{\circ} \mathrm{C}$ per minutes to $320^{\circ} \mathrm{C}$ and held for 5 minutes. Electron impact ionization for mass spectroscopy was done at ionization energy of $70 \mathrm{eV}$. The oil was diluted with $98 \%$ hexane and $2 \mu 1$ of the diluted sample was automatically injected into Agilent Tech. model 5973 mass spectrometer. The constituent compounds were identified using the Chem-Office 
software attached to the MS library. The names and structures of the component oils were confirmed using the database of National Institute of Standard and Technology (NIST).

\section{Results}

The retention time, percentage concentration, molecular formula, molecular weight and structures of the essential oils in the extracts of the Pileus (Cap), Reticulum (Cap-base) and Stipe (Stem) of $P$. tuber-regium are shown in Tables 1, 2, and 3 respectively. Propanoic acid had the highest percentage concentration in the extract obtained from the pileus, with a value of $29.763 \%$ followed by Propanamide with a value of $23.641 \%$. Extract obtained from the reticulum has Hexadecanoic acid, methyl ester as its predominant compound with a value of $23.638 \%$ followed by Eicosane, 2-methylwith a value of $20.435 \%$. The highest compound observed in the extract obtained from stipe was Hexadecanoic acid, methyl ester with a value of $26.677 \%$ followed by trans-13-Octadecenoic acid, methyl ester with a value of $25.837 \%$.

Table 1: Essential oil in Pileus (Cap) of P. tuber-regium

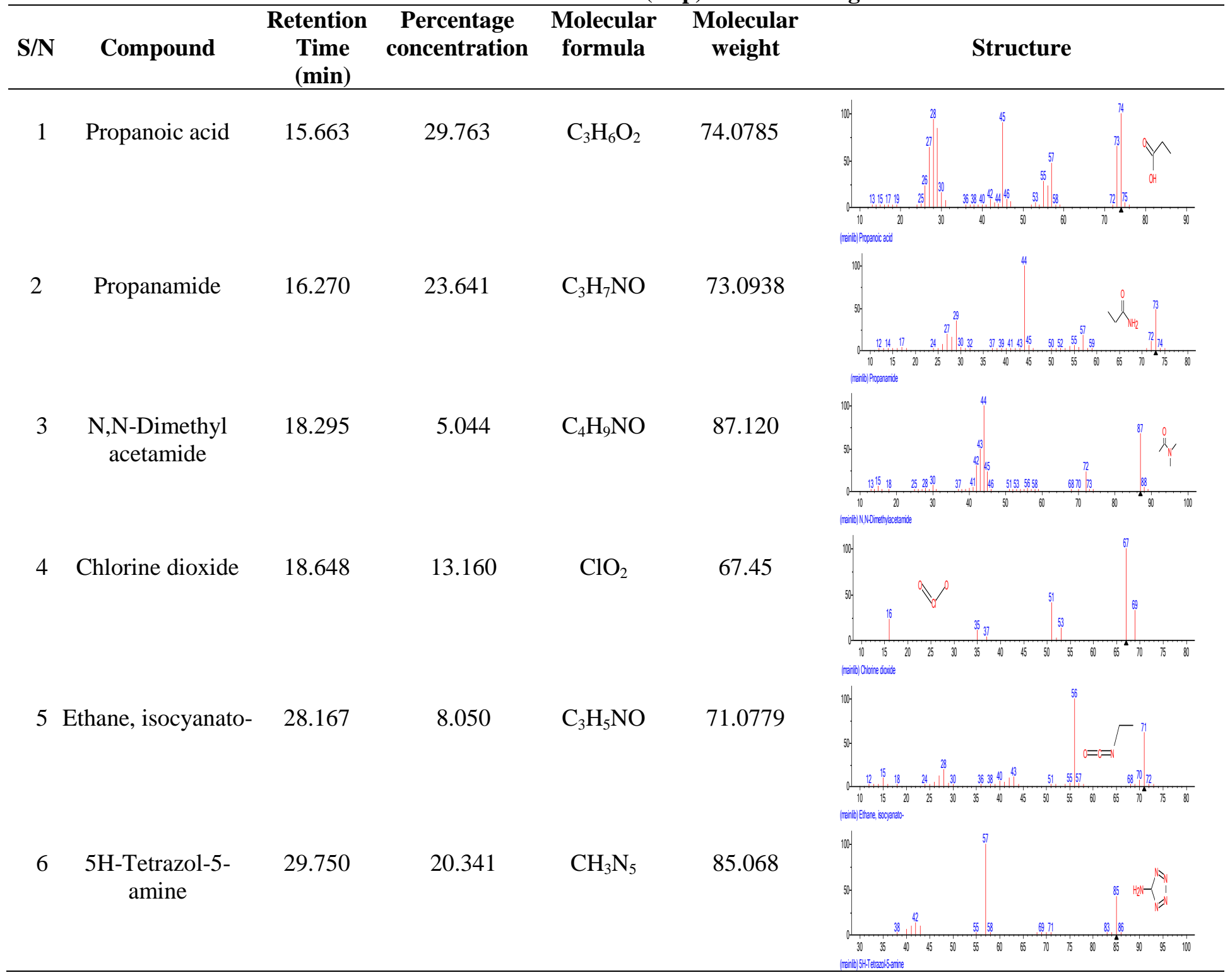


Table 2: Essential oil in the Cap-base (Reticulum) of P. tuber-regium

\begin{tabular}{lccccc}
\hline S/N Compound & $\begin{array}{c}\text { Retention } \\
\text { Time } \\
(\mathrm{min})\end{array}$ & $\begin{array}{c}\text { Percentage } \\
\text { concentration }\end{array}$ & $\begin{array}{c}\text { Molecular } \\
\text { formula }\end{array}$ & $\begin{array}{c}\text { Molecular } \\
\text { weight }\end{array}$ & Structure
\end{tabular}

1 Hexadecanoic

15.693

23.638

$\mathrm{C}_{17} \mathrm{H}_{34} \mathrm{O}_{2}$

270.4507

acid, methyl

ester

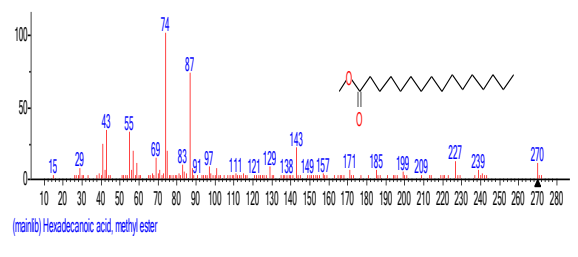

2 n-Hexadecanoic 16.289

20.170

$\mathrm{C}_{16} \mathrm{H}_{32} \mathrm{O}_{2}$

256.4241

acid

3 Spiropentane,

18.641

4.584

$\mathrm{C}_{9} \mathrm{H}_{16}$

124.2233

butyl-

4

$1,1,1,5,7,7,7-$

26.565

9.199

$\mathrm{C}_{13} \mathrm{H}_{40} \mathrm{O}_{5} \mathrm{Si}_{6}$

444.967

Heptamethyl-

3,3-bis(trimeth

ylsiloxy)tetrasil

oxane

$5 \quad 1,1,1,5,7,7,7-$

27.898

10.578

$\mathrm{C}_{13} \mathrm{H}_{40} \mathrm{O}_{5} \mathrm{Si}_{6}$

444.967

Heptamethyl-

3,3-bis(trimeth

ylsiloxy)tetrasil

oxane

6 Methoxyacetic

28.187

11.396

$\mathrm{C}_{16} \mathrm{H}_{32} \mathrm{O}_{3}$

272.429

acid, 2-tridecyl

ester

$7 \quad$ Eicosane, 2-

29.768

20.435

$\mathrm{C}_{21} \mathrm{H}_{44}$

296.5741
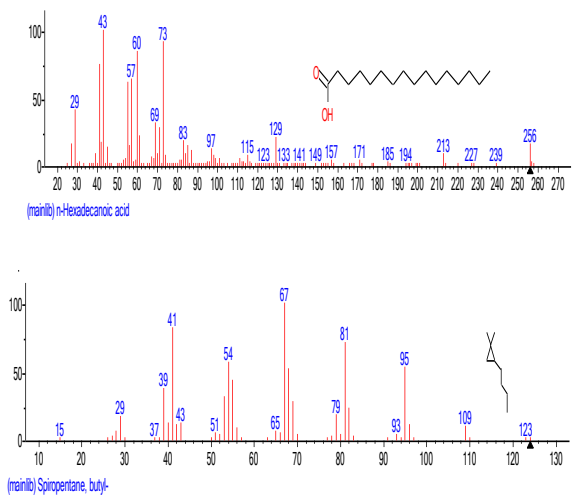

methyl-
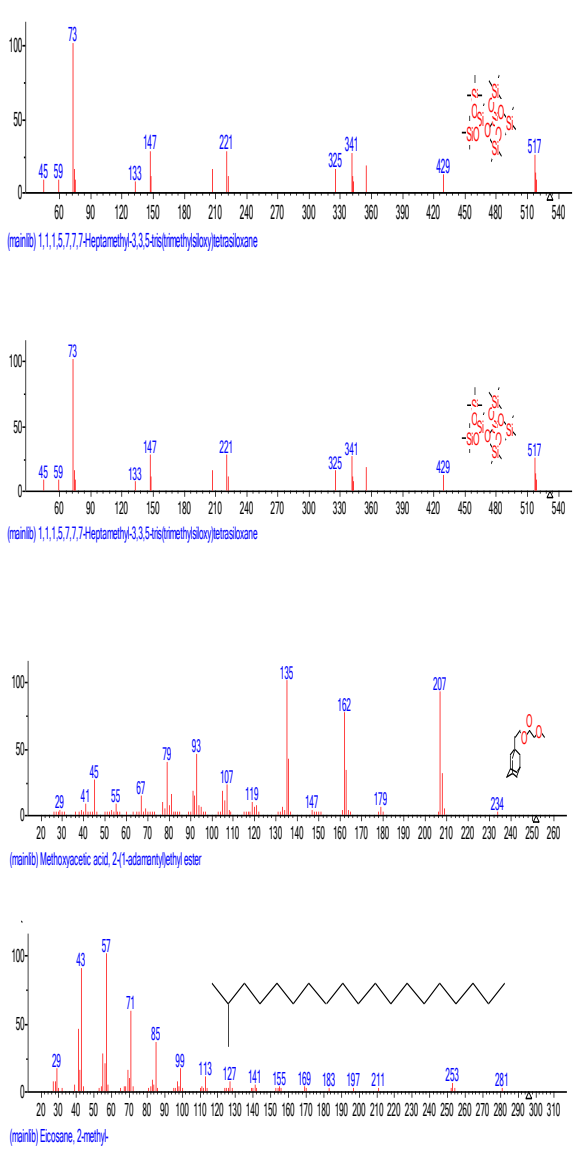
Table 3: Essential oil in the Stipe (Stem) of P. tuber-regium

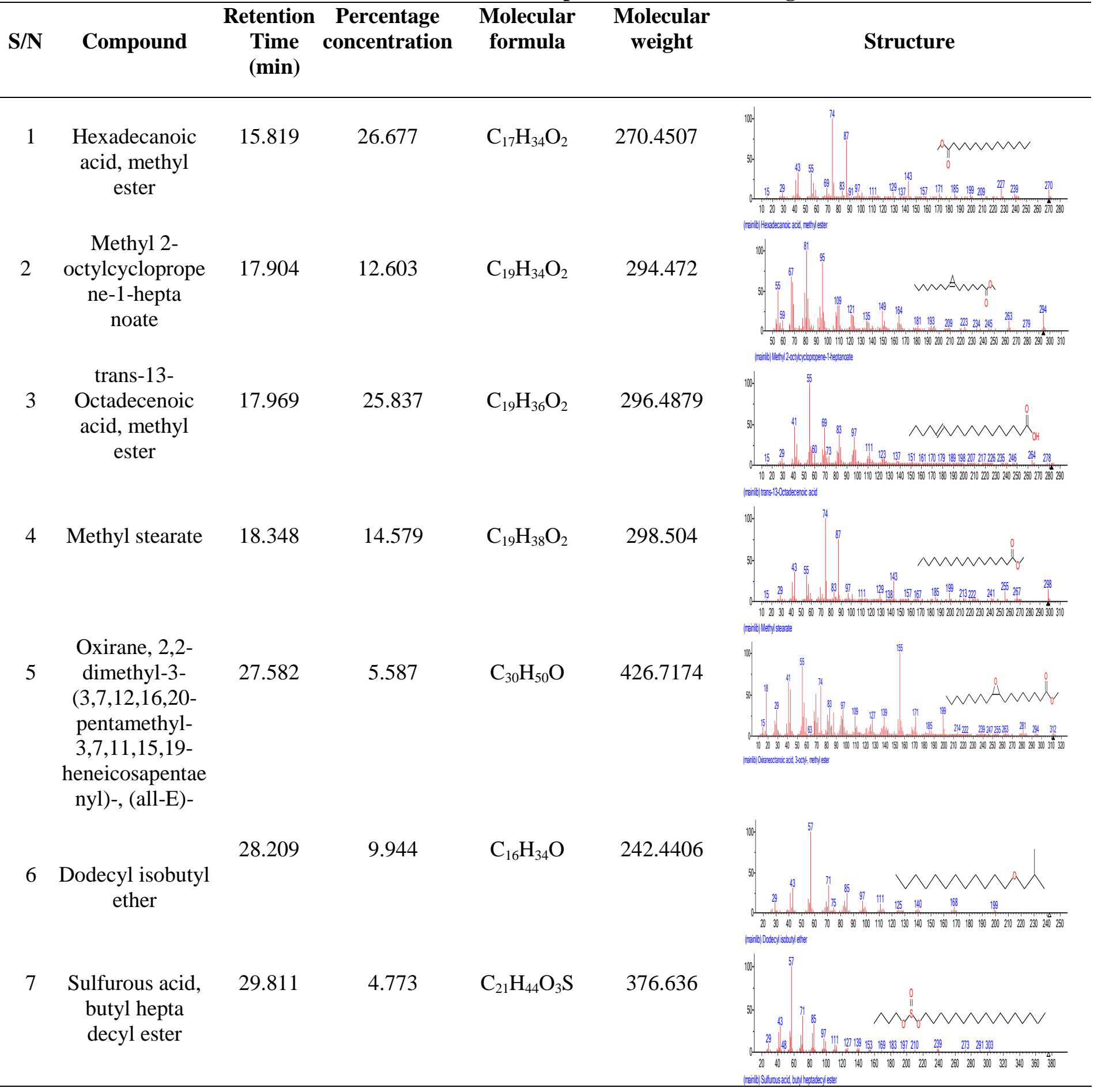

\section{Discussion}

The high concentration of propionic in the stipe of this mushroom may be of protective and preservative mechanism from animal predators and microbial attack. The unpleasant pungent smell of this carboxylic acid irritates animals from attacking and feeding on this mushroom. The ability of propionic acid to inhibit the growth of mold and bacteria not only serve as a protective mechanism, but also preserve the mushroom from spoilage due to microbial attack. This corroborates the work of ${ }^{[5]}$, which reported the use of sodium and calcium salts of propionic acid in the preservation of baked product. Moreover, propionic acid has been in use 
as a food additive in the European Union (EU) ${ }^{[6]}$, USA ${ }^{[7]}$, Australia and New Zealand ${ }^{[8]}$, with E number E280. Although propionic acid is produced as propionyl-CoA through catabolic degradation of fatty acids with odd numbers of carbon atoms, it can also be produce during the breakdown of certain amino acids. The generation of succinyl-CoA (an intermediate of citric acid cycle) through propionic acid degradation in vertebrates shows that the high concentration of propionic acid in this mushroom will have no adverse effect to human consumers except in rare cases of propionic acidemia.

The high concentration of chlorine dioxide in the stipe of this mushroom also adds to its protective arsenal. Chlorine dioxide has many applications both as an oxidizer and a disinfectant even at low concentrations ${ }^{[9]}$. It is one EPA registered biocide that is not negatively affect by $\mathrm{pH}$, silica and phosphate and it does not lose potent over time. Chlorine dioxide can also be used in the treatment of blueberries, raspberries and strawberries against yeast and molds. This indicates that its high concentration in this mushroom serves as a broad spectrum antimicrobial agent that also helps to protect the mushroom against bacterial and fungal infection. Propanamide and Tetrazole presence of in the pilus of this mushroom may not be of defense or protective importance but rather of medicinal significance. Propanamide is a monosubstituted amide which reacts in different organic processes to form compounds which may be of pharmaceutical use to humans. For example, the generation of propanamides group via the insertion of methylene group to a 3-nitro-1H-1,2,4-triazolebased acetamides enhances its potency against chagasic and human African trypanosomiasis ${ }^{[10]}$. Tetrazole and its derivatives have also enjoyed pharmaceutical recognition not only because of their unique structure, but also because of their applications as antihypertensive, anticonvulsant, antialergic and antibiotic agents ${ }^{[11]}$. Moreover, antimicrobial, antifungal, anticancer, antinociceptive, antidiabetic, anti-inflammatory, analgesic as well as cyclooxygenase inhibitory activities of tetrazole have also been reported ${ }^{[11]}$.

The seven compounds observed in the capbase of this mushroom were different from those observed in the pilus. Though this variation shows a possible localization or confinement of compounds in the different parts of the mushroom, it also reflects the relevance and potentials of the different parts of this mushroom. For instance, the methyl ester of Hexadecanoic acid observed in the cap-base and the stipe of this mushroom not only induce autolysis of membranous structures but also inhibits both cellular phagocytic activity and nitric oxide (NO) production. It also reduces tumor necrosis factor alpha (TNFa), Prostaglandin E2 (PGE2), and Interleukin 10 (IL-10) without altering the ATP levels. Though the high concentration of eicosane in the cap-base of this mushroom may neither be of protective nor medicinal value, it may be responsible for the waxy nature of the cap-base. Moreover, its near unreactive nature may be responsible for the bridge in the movement of compounds form the pilus to the stipe and vice versa. Eicosane is a colourless, nonpolar molecule that is nearly unreactive except when ignited. It is practically insoluble in water and its phase transition at moderate temperature makes it a viable compound for phase change material ${ }^{[12]}$.

Though the pesticidal, insectidal and nematicidal properties of n-Hexadecanoic acid acid, whose high percentage concentration was also observed in the cap-base of this mushroom, serves as a protective mechanism and may be responsible for the nemato-phagocytic potential of this mushroom, it also has some relevant medicinal properties. n-Hexadecanoic acid has shown some medicinal properties such as cancer preventive, antioxidant, hypochloesterolemic, antiandrogenic, haemolytic, and 5-Alpha reductase inhibitory properties ${ }^{[13]}$. The use of oils reach in nhexadecanoic in traditional medicine for the treatment of rheumatoid arthritis ${ }^{[14]}$, is attributed to the competitive inhibitory activity of nhexadecanoic on phospholipase A2 ${ }^{[15]}$. Aside hexadecanoic acid, methyl ester, whose high percentage was observed in the pilus and stipe of this mushroom, high concentration of trans-13octadecanoic acid, methyl ester was also observed in its stipe. Scientific reports on trans-13octadecanoic acid indicates that its presence in this mushroom may not be of either preservative or protective significance but rather of medicinal importance. Though Krishnamoorthy and Subramaniam, (2014), reported the flavoring potentials of trans-13-octadecanoic acid, its medicinal role as an anti-inflammatory, 
antiandrogenic, cancer preventive, dermatitigenic, antileukotriene-D4, hypocholesterolemic, 5alphareductase inhibitor, anemiagenic roles outweighs its protective potentials as an insectifugal agent $^{[16]}$.

\section{Conclusion}

The localization of phytochemicals in the different parts of the basidiocarp of this mushroom shows that each part of the basidiocarp has the potentials to synthesize its required compounds which maybe of relevance as either a protective or presevative compound to the mushroom.

\section{References}

1 Oso BA. Pleurotus tuber-regium from Nigeria. Mycologia 1977; 69(2): 271-279

2 Vilgalys, R.; Moncalvo, J. M.; Liou, S. R.; Volovsek, M. In: Recent advances in molecular systematics of the genus Pleurotus, Proceedings of 2nd International Conference of the World Society for Mushroom Biology and Mushroom Products, University Park, Pennsylvania State University, June 9-12, 1996; Royse, D.J. Ed.; World Society for Mushroom Biology and Mushroom Products: Pennsylvania, USA, 1996; pp. 91-101.

3 Okhuoya, J. A.; Okogbo, F. O. Induction of edible sclerotia of Pleurotus tuber-regium (FR) Sing, in the laboratory. Annals Appl. Biol., 1990, 117, 295-298.

4 Raven, J. A. The role of vacuoles. The new Phytologist, 1987, 106(3), 357-422.

5 Bertleff, W.; Roeper , M.; Sava, X. Carbonylation. Ullmann's Encyclopedia of Industrial Chemistry, Wiley-VCH, Verlag, Weinheim, Germany, 2010.

6 United Kingdom Food Standards Agency (UKFSA): Current EU approved additives and their E Numbers; UK Food Standards Agency (FSA)http://www.ukfoodguide.net/enumeric.ht $\underline{\text { m }}$ (Accessed 21 July, 2016).

7 United States Food and Drug Administration (USFDA): Listing of Food Additives Status Part II; US Food and Drug Administration. http://www.fda.gov/Food/FoodIngredientsPack aging/ FoodAdditives/ucm (Accessed 22 June, 2011).

8 Australia New Zealand Food Standards. Standard 1.2.4 - Labelling of ingredients. Australia New Zealand Food Standards Code. Comlaw.au.https://www.legislation.gov.au/Det ails/F2011C00827 (Accessed May, 2011).

9 Vogt, H.; Balej, J.; Bennett, J. E.; Wintzer, P.; Sheikh, S. A.; Gallone, P.; Vasudevan, S.; Pelin, K. Chlorine Oxides and Chlorine Oxygen Acids. Ullmann's Encyclopedia for Industrial Chemistry. Wiley-VCH, Verlag, Weinheim, Germany, 2010.

10 Papadopoulou MV, Bloomer WD, Rosenzweig HS, Wilkinson SR, Szular J, Kaiser M. Nitrotriazole-based acetamides and propanamides with broad spectrum antitrypanosomal activity. Eur J Med Chem 2016; 123: 895-904 DOI: 10.1016/j.ejmech.2016.08.002

11 Mohammed, J. H. Biological activities importance of Tetrazole Derivatives. Eur. Acad. Res., 2016, 3(12), 12803.

12 National Center for Biotechnology. Eicosane Compound Summary. PubChem Compound Information, Identification and Related Records.https://pubchem.ncbi.nlm.nih.gov/co mpound/eicosane (Accessed 16 September, 2004).

13 Vijisaral , E. D.; Arumugam , S. GC-MS analysis of bioactive constituents of Indigofera suffruticosa leaves. J. Chem. Pharmaceut. Res., 2014, 6 (8), 294-300.

14 McGaw LJ, Jager AK, van Staden J. Isolation of antibacterial fatty acids from Schotia brachypetala. Fitoterapia 2002; 73(5): 431433

15 Giner-Larza, E. M.; Mánez, S.; Giner-Pons, R. M.; Carmen, R. M.; Ríos, J. L. Antiinflammatory and anti-phospholipase A2 activity of extracts from lanostane-rich species. J. Ethnopharm., 2000, 73, 61-69.

16 Krishnamoorthy K, Subramaniam P. Phytochemical Profiling of Leaf, Stem, and Tuber Parts of Solena amplexicaulis (Lam.) Gandhi Using GC-MS. Int Sch Res Notices 2014; 2014 : 567409 DOI: $\underline{10.1155 / 2014 / 567409}$ 